\begin{tabular}{|c|c|c|c|c|c|c|}
\hline \multirow{4}{*}{ Impact Factor: } & ISRA (India) & 3.117 & SIS (USA) & $=0.912$ & ICV (Poland) & $=6.630$ \\
\hline & ISI (Dubai, UAE & $=0.829$ & РИНЦ (Russia & $=0.156$ & PIF (India) & $=1.940$ \\
\hline & GIF (Australia) & $=0.564$ & ESJI (KZ) & $=5.015$ & IBI (India) & $=4.260$ \\
\hline & JIF & $=1.500$ & SJIF (Morocco & $=5.667$ & & \\
\hline
\end{tabular}

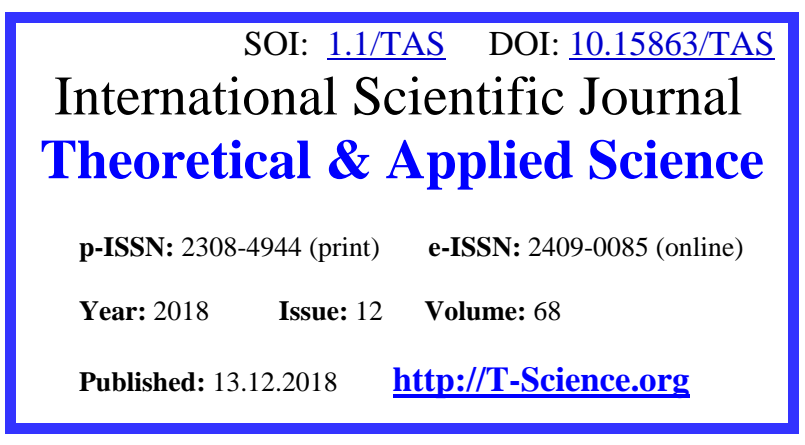

SECTION 31. Economic research, finance, innovation, risk management.
QR - Issue

QR - Article

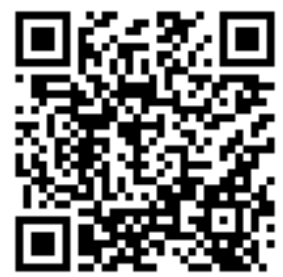

Sergei Rudolfovich Semenov Candidate of economic science Director of state enterprise Information Marketing Centre «Aiylmaalymat» of Ministry of Agriculture of Food Industry and Land Reclamation of Kyrgyz Republic, Doctorate of Kyrgyz Economic University named after M. Ryskulbekov

\title{
AGRARIAN POLICY AND INTEGRATED INFORMATION SECURITY IN THE AGRICULTURAL INDUSTRY
}

\begin{abstract}
This article discusses the main directions of the agrarian policy and the information communication of the industry using the possibility of integrated interstate systems for providing electronic data to users of the information network. The main directions of information interaction in the EAEU member states were determined, taking into account the development of common infrastructure in the information exchange system with the Kyrgyz Republic. The directions of the development of state-owned integrated information systems, their relationship with the general information network of the EAEU member states, and integration processes are shown.

Key words: Agrarian policy, integration, information, information systems, information networks.

Language: Russian

Citation: Semenov, S. R. (2018). Agrarian policy and integrated information security in the agricultural industry. ISJ Theoretical \& Applied Science, 12 (68), 57-60.

Soi: http://s-o-i.org/1.1/TAS-12-68-11 Doi: croskef https://dx.doi.org/10.15863/TAS.2018.12.68.11
\end{abstract}

\section{АГРАРНАЯ ПОЛИТИКА И ИНТЕГРИРОВАННОЕ ИНФОРМАЦИОННОЕ ОБЕСПЕЧЕНИЕ В СЕЛЬСКОХОЗЯЙСТВЕННОЙ ОТРАСЛИ}

Аннотация: В данной статье рассматривается основные направления аграрной политики и информационная связь отрасли с применением возможности интегрированных межгосударственных систем по предоставлению пользователям информационной сети электронных данных. Определены основные направления информационного взаимодействия в государствах-членах ЕАЭС, с учетом развития общей инфраструктуры в системе обмена информации с Кыргызской Республикой. Показаны направления развития государственных отраслевых интегрированных информационных систем, их взаимосвязь с общей информационной сети государствах-членах ЕАЭС, с учет интеграциионных проиессов.

Ключевые слова: Аграрная политика, интеграцчия, информация, информациионные системы, информационные сети.

\section{Introduction}

Сельское хозяйство составляет важнейший экономический сектор в экономики каждой страны, отвечает за продовольственную безопасность и способствует росту благосостояния сельского населения. В процессе развития сельскохозяйственной отрасли, сложилось много проблем по увеличению темпов роста сельского хозяйства, сбыта, переработки, хранения, реализации продукции. Решение проблем всегда отражается в выработке определенной аграрной политики для проработки комплекса мер для развития отрасли. Организация самого производства в сельскохозяйственной отрасли предусматривает осуществление системных мер по эффективному использованию материальных, технических, финансовых ресурсах, с целью получения большего объема продукции высокого качества [1]. Поэтому разработка направлений развития приоритетных секторов в сельскохозяйственной отрасли основывается на аграрной политики, где 


\begin{tabular}{|c|c|c|c|c|c|c|}
\hline \multirow{4}{*}{ Impact Factor: } & ISRA (India) & $=3.117$ & SIS (USA) & $=0.912$ & ICV (Poland) & $=6.630$ \\
\hline & ISI (Dubai, UAE & $=0.829$ & РИНЦ (Russia) & $=0.156$ & PIF (India) & $=1.940$ \\
\hline & GIF (Australia) & $=0.564$ & ESJI (KZ) & $=\mathbf{5 . 0 1 5}$ & IBI (India) & $=4.260$ \\
\hline & JIF & $=1.500$ & SJIF (Morocco) & $=5.667$ & & \\
\hline
\end{tabular}

аграрная политика выступает, как определенная деятельность государства, способствующая развитию агропромышленных комплексов (АПК) и обеспечивающая национальную продовольственную безопасность, жизнедеятельность сельского населения [2].

\section{Materials and Methods}

В соответствии с этими задачами вырабатываются направления агропромышленной политики в каждой стране, в том числе и в Кыргызской Республики такими направлениями являются:

- совершенствование законов и правовых актов в сфере агропромышленного сектора экономики;

АПК;

$$
\text { - государственная политика в развитии }
$$

государственная поддержка по производству, переработки сельскохозяйственной продукции;

обеспечение макроэкономических показателей и прогнозирование производства в сельском хозяйстве;

обеспечение ветеринарных и

фитосанитарных мер;

- развитие экспорта сельхозпродукции и продуктов питания;

- научное и инновационное развитие в отрасли;

интегрированное информационное обеспечение [3].

Одним из приоритетов развития всей экономики страны и сельского хозяйства, определяют цели на инновационное развитие самой отрасли, с учетом общего развитие интегрированного обеспечения информационного сельскохозяйственное выступающего объектом компьютеризации и средством перехода отрасли к цифровой экономики. Развитие глобальных информационных систем и компьютеризация привели к новым возможностям в сельском хозяйстве, что способствует повышению производительности труда в отрасти. «На современном этапе развития мирового сельскохозяйственного производства в значительной мере нивелируются национальные различия в условиях производства и все шире применяются отработанные универсальные технологии с гарантированным результатом» [4]. Эффективность в отрасли зависит от обеспеченности органов управления, фермеров, товаропроизводителей достоверной экономической, справочной, коммерческой, научной информацией, а определение эффективных методов доведение этой актуальной информации до пользователей остается одной из сложных задач. Предоставление пользователям рыночной информации в интегрированных информационных системах, будет способствовать построению общего взаимопонимания и согласованного развития на внешних и внутренних рынках, что позитивно отразиться на торговых отношениях. Основываясь на текущем информационном обеспечении и путях развития цифровой экономики, сегодня учитываются все направления информационного взаимодействия и развития структуры информации, которая дает определенный экономический и социальный эффект, таким как увеличение темпов роста, к созданию интеллектуальных рабочих мест, что активно влияет на развитие информационной инфраструктуры сельскохозяйственной отрасли. Информационные процессы, которые направлены на инновационные преобразования в обществе, способствуют внедрению высоких технологий информатизации, разработке и принятию новых управленческих решений, что приводит к формированию современной социальноориентированной экономики, где «рыночные отношения требуют активизации деятельности инновационных формирований по расширению функций, являющихся следствием возрастающих запросов со стороны потребителей и способствующих повышению эффективности производства» [5]. Интеграция технологий и применение их в различных информационных мировых системах, повлияло и на развития информатизации в ряде стран, в Кыргызской Республике это направление было взято за основу, как самостоятельная государственная политика страны в области создания своих информационных систем и ресурсов. Вхождение Кыргызской Республики в Евразийский экономический союз (ЕАЭС) только способствовало дальнейшему развитию информационной структуры в страны, с учетом общих принципов развития информации в ЕАЭС. Страны ЕАЭС получили ряд преимуществ общеэкономического характера, таких как, обеспечение равного доступа на аграрных рынках стран, формирования совместных предприятий и увеличения объема инвестиций в отраслях АПК, а также и других направления развития, которые отражаются в создании и работе общей интегрированной информационной системе.

Государственная политика стран ЕАЭС в области единой интеграции и цифровой экономики, на протяжении последних лет определила степень перехода и уровень при реализации общих информационных процессов, что было отраженно в «Договоре ЕАЭС», в разделе договора по информационному взаимодействию и статистики. Данное 


\begin{tabular}{|c|c|c|c|c|c|c|}
\hline \multirow{4}{*}{ Impact Factor: } & ISRA (India) & $=3.117$ & SIS (USA) & $=0.912$ & ICV (Poland) & $=6.630$ \\
\hline & ISI (Dubai, UAE & $=0.829$ & РИНЦ (Russia) & $=0.156$ & PIF (India) & $=1.940$ \\
\hline & GIF (Australia) & $=0.564$ & ESJI (KZ) & $=5.015$ & IBI (India) & $=4.260$ \\
\hline & JIF & $=1.500$ & SJIF (Morocco) & $=5.667$ & & \\
\hline
\end{tabular}

взаимодействие определяет, что для обеспечения эффективного взаимодействия и координации государственных информационных ресурсов и информационных систем стран ЕАЭС проводятся согласованная политика в области информатизации и информационных технологий [6], а также определяются процессы создания и развития интегрированной информационной системы, как единого информационного ресурса.

Применение современных информационнопрограммных разработок и общих систем коммуникации в создании интегрированных информационных систем, позволяет обеспечить быстрый сбор и размещение информации в базах данных, а также оперативно проводить расчеты в различных интеграционных ресурсах и системах. Использования пользователями разных баз данных в информационных ресурсах своих стран и стран ЕАЭС, позволяет повысить скорость передачи данных в общем информационном шлюзе ЕАЭС, в инфраструктуре задействован как удаленный доступ через интернет, так и доступ в сети государственных органов поддерживающих свои базы данных. В области сельского хозяйства, странами ЕАЭС создана информационная подсистема агропромышленного комплекса, которая входит в единую интегрированную информационную систему. Информационная подсистема агропромышленного комплекса содержит информацию по единым реестрам и общим ресурсам в сельском хозяйстве, состояние и прогнозы развития АПК, с индикативными показателями балансов спроса и предложения.

Подсистема агропромышленного комплекса стран ЕАЭС является доступной в интернет pecypcax и предназначена для обмена информацией между население, бизнес и государственными структурами странам ЕАЭС, Функциями подсистемы агропромышленного комплекса являются сбор, формирование, обработка, хранение сведений по общим информационным сельскохозяйственной частности:

сельскохозяйственных растений;

- по прогнозным показателям АПК [7];

- по ценам на сельскохозяйственную продукцию и продукцию пищевой промышленности [8];

- по данным национальных планов производства сельскохозяйственных товаров [9];

- по научным и исследовательским работам в АПК $[10]$;

- по семеноводству сельскохозяйственных растений;

- по племенным животным и селекции в области племенного животноводства;

- по агрохимическому обеспечению сельского хозяйства и защиты растений;

- по государственной поддержке сельского хозяйства.

\section{Conclusion}

По ряду показателей ресурсов аналитическая отчетность, структура

общих формируется аналитическая отчетность, структура информации определяется в соответствии с
Решениями Совета Евразийской экономической комиссии по направлениям общей скоординрованной политики в сельскохозяйственной отрасли[7];[8];[9];[10]. Разработка и реализация подсистемы информационно

-аналитического обеспечения, позволит проводить мониторинг экономического состояния сельскохозяйственных отраслей стран ЕАЭС и получать качественные экспертные заключения по результатам представленных аналитических материалов и отчетности, что будет способствовать выработке определенных рекомендаций по рациональному ведению аграрной политики и поможет создать качественную систему управления сельскохозяйственной отрасли, а также совершенствовать методы и модели получение необходимой информации в общих информационных системах и ресурсах стран ЕАЭС.

\section{References:}

1. Shakirov, F. K. (2003). Organization of agricultural production. (p.7). M.: KolosS.

2. (2018). Glossary. Agrarian Policy. Retrieved December 01, 2018, from https://finances.social/regulirovanie-ekonomikigosudarstvennoe/glossariy-80353.html
3. (2018). Materials of the Ministry of Agriculture, Food Industry and Land Reclamation of the Kyrgyz Republic. Retrieved December 01, 2018, from https://agroprod.kg/

4. Kashubo, N. (2007). Management of information process in Agro Industry Complex 


\begin{tabular}{|c|c|c|c|c|c|c|}
\hline \multirow{4}{*}{ Impact Factor: } & ISRA (India) & $=3.117$ & SIS (USA) & $=0.912$ & ICV (Poland) & $=6.630$ \\
\hline & ISI (Dubai, UAE & $=0.829$ & РИНЦ (Russia) & $=0.156$ & PIF (India) & $=1.940$ \\
\hline & GIF (Australia) & $=0.564$ & ESJI (KZ) & $=\mathbf{5 . 0 1 5}$ & IBI (India) & $=4.260$ \\
\hline & JIF & $=1.500$ & SJIF (Morocco) & $=5.667$ & & \\
\hline
\end{tabular}

(AIC). AIC: economics and management №4, 51-56;

5. Ushachev, I. G., Oglobina, E. S., \& Tribulina, A. I. (2007). Innovation activity in agrarian sector of Russian economics. (p.123). M.: KolosS.

6. (2014, May 24). Treaty on the Eurasian Economic Union. Astana. Retrieved December 01, 2018, from http://online.zakon.kz/document/?doc $\mathrm{id}=3156$ $\underline{5247}$

7. (2015). Decision of the Council of the Eurasian Economic Commission of February 4, 2015 No. 2 "On the list of indicative indicators of the development of the agro-industrial complex of the member states of the Eurasian Economic Union». Retrieved December 01, 2018, from http://online.zakon.kz/document/?doc_id=3166 $\underline{4315}$

8. (2015). Decision of the Council of the Eurasian Economic Commission dated February 12, 2015 No. 15 «On the nomenclature of agricultural products and food industry products produced in the member states of the Eurasian Economic Union, for which price monitoring and analysis of competitiveness is carried out by the Eurasian Economic Commission». Retrieved December 01, 2018, from

http://online.zakon.kz/Document/?doc_id=3898 $\underline{5918}$

9. (2016). Recommendation of the Board of the Eurasian Economic Commission of September 6, 2016 No. 15 "On the Methodology for calculating the forecast balance of supply and demand of the member states of the Eurasian Economic Union on agricultural products, food, flax, raw leather, cotton and wool. Retrieved December 01, 2018, from http://online.zakon.kz/Document/?doc id=3192 3357

10. (2015). Recommendation of the Board of the Eurasian Economic Commission dated July 8, 2015 № 14 «On the list of promising research and development work in the field of agroindustrial complex of the member states of the Eurasian Economic Union until 2020». Retrieved December 01, 2018, from http://online.zakon.kz/Document/?doc id=3598 $\underline{6437}$ 